\title{
RENCANA PENGELOLAAN DAN ZONASI KAWASAN KONSERVASI PERAIRAN PULAU ENGGANO PROVINSI BENGKULU
}

\author{
Zamdial, Deddy Bakhtiar, Ari Anggoro, Dede Hartono, Ali Muqsit \\ Program Studi Ilmu Kelautan, Fakultas Pertanian, Universitas Bengkulu, \\ Bengkulu, Indonesia \\ E-mail : zamdial_et@yahoo.co.id
}

Received March 2020, Accepted April 2020

\begin{abstract}
ABSTRAK
Pulau Enggano merupakan salah satu pulau kecil terluar di Indonesia yang terletak di perairan Pantai Barat Sumatera, Samudera Hindia. Pulau Enggano adalah sebuah kecamatan dalam wilayah Kabupaten Bengkulu Utara, Provinsi Bengkulu. Untuk kepentingan ekologis dan ekonomi, semua potensi sumberdaya hayati kelautan yang ada di Pulau Enggano, harus dikelola secara optimal dan berkelanjutan. Tujuan penelitian ini adalah untuk menyusun Dokumen Rencana Pengelolaan dan Zonasi Kawasan Konservasi Perairan Daerah (KKPD) Pulau Enggano, Provinsi Bengkulu. Penelitian dilakukan dengan metode survei. Data primer yaitu kondisi bio-fisik dan persepsi masyarakat, dikumpulkan dengan metode obesrvasi, wawancara dan FGD (Focus Group Discussion). Data dikumpulkan dengan metode studi kepustakaan. Semua data di analisis dengan metode deskriptif-kualitatif. Luas wilayah daratan Pulau Enggano, $\pm 400,6 \mathrm{~km}^{2}$ atau \pm 40.600 hektar. Ekosistem utama adalah hutan mangrove $\pm 1414,78$ ha $\left(141,478 \mathrm{~km}^{2}\right)$, dan terumbu karang $\pm 5.097 \mathrm{ha}( \pm$ $50,97 \mathrm{~km}^{2}$ ). Potensi sumberdaya hayati lainnya adalah padang lamun, berbagai jenis rumput laut, ikan karang, ikan pelagis dan ikan demersal yang ekonomis penting. Kebijakan pengelolaan KKPD Pulau Enggano diarahkan untuk pemanfaatan kegiatan pariwisata dan perikanan berkelanjutan. Lokasi KKPD Pulau Enggano di tetapkan di Kawasan Desa Banjarsari dan Desa Kahyapu. Visi Pengelolaan Kawasan Konservasi Perairan Daerah (KKPD) Pulau Enggano Kabupaten Bengkulu Utara adalah "Mewujudkan pengelolaan dan pemanfaatan Kawasan Konservasi Perairan Enggano secara optimal, terpadu, dan berkelanjutan, sehingga bermanfaat bagi kesejahteraan dan kemakmuran masyarakat". Pengelolaan KKPD Pulau Enggano untuk Rencana Jangka Panjang (RJP) adalah selama 20 tahun yang meliputi 4 tahapan Rencana Pengelolaan jangka Menegah (RPJM).
\end{abstract}

Kata Kunci : Enggano, KKPD, Pengelolaan, Pariwisata, Perikanan 


\begin{abstract}
MANAGEMENT PLAN AND ZONING OF THE CONSERVATION AREA OF THE ENGGANO ISLAND, BENGKULU PROVINCE. Enggano Island is one of the outer small islands in Indonesia which is located in the waters of the West Coast of Sumatra, Indian Ocean. Enggano Island is a district in the region of North Bengkulu Regency, Bengkulu Province. For ecological and economic interests, all potential of marine living resources that exist on the island of Enggano, must be managed by optimally and sustainably. The purpose of this study was to compile the Document of Management Plan And Zoning of The Enggano Island Regional Marine Conservation Area (RMCA), Bengkulu Province. The study was conducted by survey method. Primary data, namely bio-physical conditions and community perceptions, were collected by observation, interviews and FGD (Focus Group Discussion) methods. Secondary data were collected by the literature study method. All data were analyzed by descriptivequalitative methods. The total land area of Enggano Island, $\pm 400.6 \mathrm{~km}^{2}$ or $\pm 40,600$ hectares. The main ecosystem is mangrove forest \pm 1414.78 ha $\left(141.487 \mathrm{~km}^{2}\right)$, and coral reef $\pm 5,097$ ha $\left( \pm 50.97 \mathrm{~km}^{2}\right)$. Other potential biological resources are seagrass beds, various types of seaweed, reef fish community, pelagic and demersal fish which are economically important. The management policy of the Enggano Island RMCA is directed for the utilization of sustainable tourism and fisheries activities. The location of the Enggano Island RMCA was determined in the Banjarsari and Kahyapu Villages. The Vision of the Management of the Enggano Island KKPD of North Bengkulu Regency is "Realizing the management and utilization of the Enggano Marine Protected Area in an integrated, optimal and sustainable manner, so that it is beneficial for the welfare and prosperity of the community". The Management of the Enggano Island RMCA for the Long-Term Plan (LTP) is for 20 years which includes 4 stages of the Medium-Term Management Plan (MTMP).
\end{abstract}

Keywords : Enggano, RMCA, Management, Tourism, Fishery

\title{
PENDAHULUAN
}

Pulau Enggano terletak di Perairan Samudera Hindia yang termasuk wilayah Perairan Pantai Barat Pulau Sumatera. Pulau Enggano ini merupakan suatu gugusan pulau-pulau kecil lainnya yaitu Pulau Satu, Pulau Dua, Pulau Merbau, Pulau Bangkai dan Pulau Karang.

Pulau Enggano terletak pada koordinat $5^{\circ} 31^{\prime} 13^{\prime \prime}$ LS dan $102^{\circ} 16^{\prime}$ 0" BT, yang secara administratif, terletak di Kecamatan Enggano, Kabupaten Bengkulu Utara, Provinsi Bengkulu, dan berbatasan dengan Negara India (Khomarudin et al., 2016). Peta Pulau Enggano dapat dilihat pada Gambar 1. 


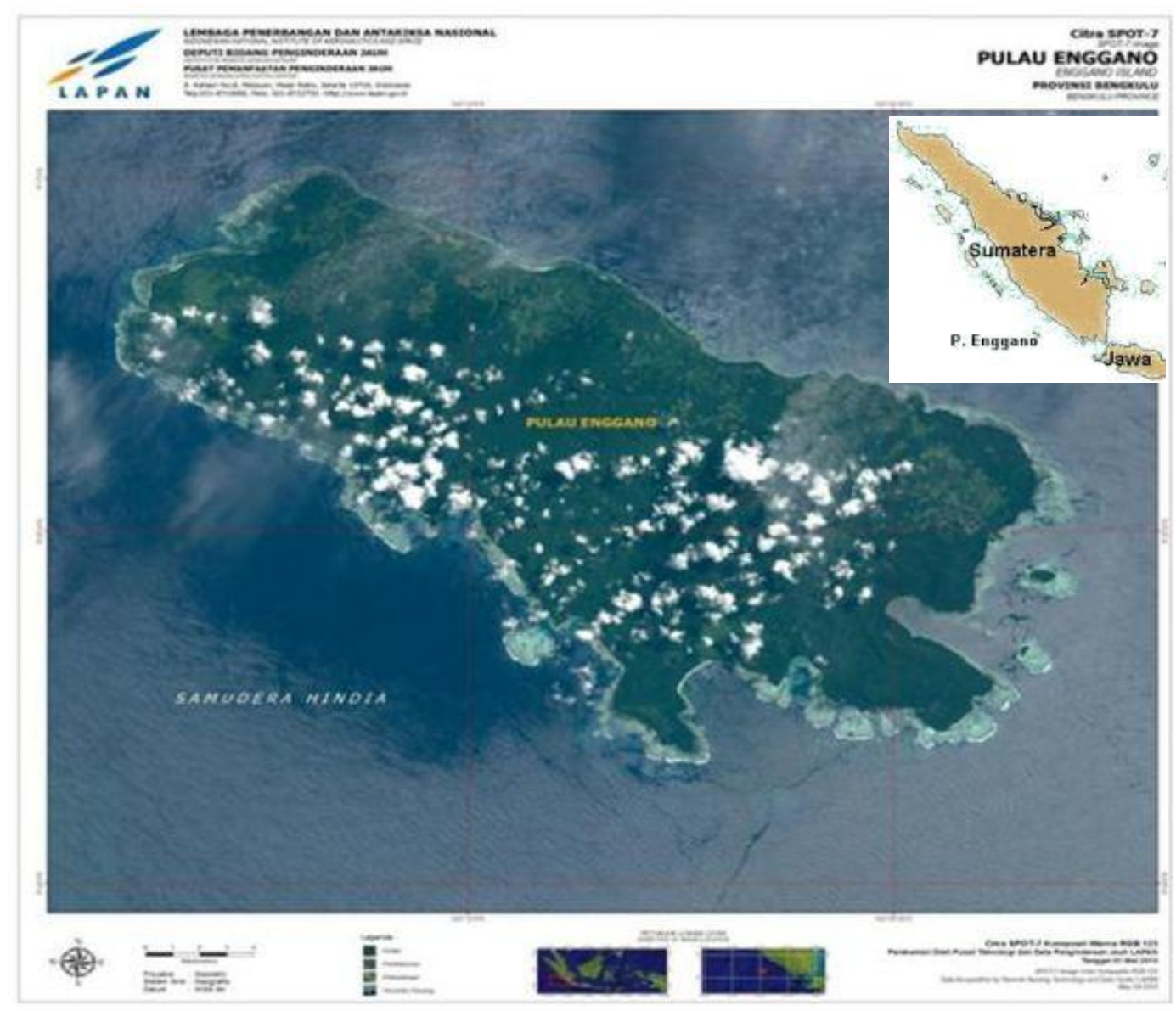

Gambar 1. Peta Citra Satelit Pulau Enggano (Sumber : Khomarudin et al., 2016)

Kawasan Pulau Enggano meliputi Pulau Enggano sebagai pulau induk, Pulau Dua, Pulau Satu, Pulau Merbau dan Pulau Bangkai, secara administratif adalah sebuah kecamatan yang menjadi bagian dari Kabupaten Bengkulu Utara, Provinsi Bengkulu. Luas wilayah daratan Pulau Enggano, sebagai pulau induk diketahui $\pm 400,6 \mathrm{~km}^{2}$ atau \pm 40.600 hektar. Pulau Enggano mempunyai 6 desa definitif, yaitu Desa Kahyapu, Desa Kaana, Desa Malakoni, Desa Apoho, Desa Meok dan Desa Banjarsari. Pusat Pemerintahan Kecamatan Enggano berada di Desa Apoho.

Pulau Enggano sebagai kawasan pulau-pulau kecil memiliki potensi utama berupa sumberdaya hayati pesisir dan laut seperti halnya ekosistem mangrove, ekosistem terumbu karang, komunitas padang lamun, sumberdaya hayati rumput laut dan sumberdaya hayati perikanan. Sebagaimana yang dikemukakan oleh Dahuri et al (1996) dalam Darsono (1999) dan Astuti et al (2008), bahwa sumberdaya hayati pesisir dan laut meliputi hutan mangrove, terumbu karang, padang lamun dan rumput laut dan perikanan laut. 
Keberadaan ekosistem terumbu karang, ekosistem hutan mangrove, komunitas padang lamun, rumput laut dan ekosistem perairan lainnya di kawasan Pulau Enggano yang memiliki keanekaragaman sumberdaya hayati (biodiversiti) yang tinggi, merupakan suatu potensi yang bernilai tinggi. Potensi sumberdaya hayati ekosistem pesisir dan laut tersebut menjadi tumpuan utama penghidupan masyarakat di Pulau Enggano dan sudah di eksploitasi sejak lama, dan menunjukkan peningkatan intensitas yang semakin tinggi dari waktu ke waktu. Potensi yang cukup besar yang ada di kawasan Pulau Enggano jika dikelola secara optimal, tentunya merupakan aset yang penting guna mendukung pembangunan sektor perikanan di Kabupaten Bengkulu Utara.

Sebagaimana yang dikemukakan oleh Sobari et al (2006), bahwa potensi sumberdaya alam wilayah pesisir dan lautan di Indonesia yang sangat besar tersebut membutuhkan pengelolaan yang baik, sehingga pemanfaatannya dapat berlangsung secara berkesinambungan, sesuai dengan konsep pembangunan berkelanjutan yang menjadi dasar konsep pembangunan nasional.

Keanekaragaman hayati yang tinggi dan potensi sumberdaya hayati pesisir dan laut yang bernilai ekonomis di kawasan Pulau Enggano perlu dijaga, dilindungi, dipertahankan dan dikelola sedemikian rupa, agar tetap lestari sehingga dapat berfungsi dan memberikan peranannya secara optimal dan berkelanjutan.

Salah satu alat pengelolaan sumberdaya pesisir dan laut yang efektif adalah dengan mengembangkan Kawasan Konservasi Perairan (KKP), yaitu mengalokasikan sebagian wilayah pesisir dan laut sebagai tempat perlindungan bagi ikan-ikan ekonomis penting untuk memijah dan berkembang biak dengan baik. Untuk mendukung keberlanjutan pemanfaatan potensi sumberdaya pesisir dan laut di kawasan Pulau Enggano, maka perlu dikembangkan sebagai suatu KKPD. Dalam upaya mendukung pengembangan kawasan Pulau Enggano sebagai KKPD, telah ditetapkan Keputusan Bupati Bengkulu Utara Nomor 175 Tahun 2014 tentang Pencadangan Kawasan Konservasi Perairan Daerah Enggano di Kecamatan Enggano Kabupaten Bengkulu Utara. Untuk mensinergikan dan mendukung program Kementerian Kelautan dan Perikanan Republik Indonesia (KKP-RI) yang sedang mengembangkan 20 juta hektar KKPD diseluruh wilayah Indonesia sampai Tahun 2020, maka pada perlu disusun Rencana Pengelolaan KKPD di Pulau Enggano, Kabupaten Bengkulu Utara.

Tujuan penelitian ini adalah untuk menyusun Dokumen Rencana Pengelolaan dan Zonasi Kawasan Konservasi Perairan Daerah (KKPD) Pulau Enggano, Provinsi Bengkulu. Maksud dari penelitian ini adalah : (1) Menghimpun data dan informasi terkait potensi dan isu permasalahan yang dihadapi dalam pengelolaan KKPD Pulau Enggano, (2) Meningkatkan pemahaman dan dukungan stakeholders terhadap pembentukan KKPD Pulau Enggano, desain sampai dukungan terhadap pemantauan, pengelolaan dan evaluasi berkala, dan (3) Menyiapkan dokumen Rencana Pengelolaan KKPD Pulau Enggano sebagai acuan dan panduan bagi seluruh stakeholders dalam pengelolaan KKPD. 
Dalam dokumen ini rencana pengelolaan di fokuskan pada KKPD Pulau Enggano, yang ditetapkan sebagai tipe kawasan Suaka Perikanan.

\section{MATERI DAN METODE}

Penelitian penyusunan Rencana Pengelolaan dan Zonasi KKPD Pulau Enggano dilakukan dengan metode survei. Dalam penelitian ini dibutuhkan berbagai data primer dan data sekunder. Data primer yang dikumpulkan terutama adalah data tentang kondisi bio-fisik dan persepsi masyarakat. Data sekunder meliputi semua data pendukung yang meliputi aspek ekonomi, sosial dan budaya.

Data primer dikumpulkan dengan metode observasi langsung di lokasi penelitian dan wawancara dengan kelompok nelayan dan kelompok masyarakat. Untuk lebih menggali persepsi masyarakat terhadap penyusunan rencana pengelolaan dan zonasi KKPD Pulau Enggano, dilakukakan Focus Group Discussion (FGD) dengan melibatkan unsur pemerintah kecamatan, pemerintah desa, kepala suku dan tokoh masyarakat, lembaga swadaya masyarakat, perguruan tinggi dan pihak swasta. Analisis data dalam pelaksanaan penelitian ini menggunakan metode deskriptif-kualitatif.

\section{HASIL DAN PEMBAHASAN}

\section{Potensi Sumberdaya Hayati Wilayah Pesisir}

Kawasan Pulau Enggano memiliki potensi utama berupa sumberdaya hayati pesisir dan laut seperti halnya ekosistem mangrove, ekosistem terumbu karang, komunitas padang lamun, sumberdaya hayati rumput laut dan sumberdaya hayati perikanan. Sebagaimana yang dikemukakan oleh Astuti et al (2008) dalam Ta'alidin (2014), bahwa sumberdaya hayati pesisir dan laut meliputi hutan mangrove, terumbu karang, padang lamun dan rumput laut dan perikanan laut.

Luas ekosistem hutan mangrove di Pulau Enggano $\pm 1414,78$ ha $\left(141,478 \mathrm{~km}^{2}\right)$. Berdasarkan interpretasi citra satelit pada Tahun 2000, luas hutan mangrove pada bagian Barat Pulau Enggano adalah $\pm 448,33$ ha, sedangkan hutan mangrove yang terdapat sebelah Timur (mengahadap kedaratan Bengkulu) adalah seluas $\pm 966,45$ ha (Bappeda Bengkulu Utara dan Laboratorium Perikanan Unib, 2004).

Secara keseluruhan jenis tumbuhan yang membangun ekosistem hutan mangrove di Pulau Enggano sangat bervariasi diantaranya Acanthus ilicifolius, Avicennia marina, Barringtonia asiatica, Bruguiera cylindrical, B. gymnorrhiza, Cerbera manghas, Ceriops tagal, Excoecaria agallocha, Hibiscus tiliaceus, Ipomoea pes-caprae, Melastoma candidum, Morinda citrifolia, Pandanus tectorius, Phemphis acidula, Pongamia pinnata, Rhizophora apiculata, R. Mucronata, R. Stylosa, Scaevola taccada, Sonneratia alba, Stachytarpeta jamaicencis, Terminalia catappa, Wedelia biflora, Xylocarpus granatum (Agustini 2014 dan Haloho, 2014). 
Ekosistem mangrove di Pulau Enggano sampai saat ini masih terjaga dengan baik. Kearifan lokal yang dikembang dengan pola budaya kerapatan suku-suku, menghendaki agar ekosistem hutan mangrove tetap dipertahankan dan tidak boleh dirusak. Pemanfaatan hutan mangrove hanya melalui usaha pencarian dan penangkapan biota-biota yang bernilai ekonomis penting yang terdapat di dalam hutan mangrove seperti ikan, kepiting dan lokan (jenis molluska). Menurut Holoho (2014), kondisi ekosistem hutan mangrove yang ada di Desa Kaana selalu dijaga dan memilki Perdes (Peraturan Desa) Nomor 4 Tahun 2009 tentang perlindungan terhadap ekosistem hutan mangrove. Selanjutnya dikemukankan oleh Agustini (2014), bahwa adanya peraturan daerah setempat tentang pelarangan perusakan ekosistem mangrove juga sangat mendukung masyarakat untuk lebih menjaga keberadan ekosistem mangrove dan mencintai ekosistem ini sebagai salah satu ekosistem yang sangat penting pada wilayah pesisir khususnya di daerah Desa Kahyapu.
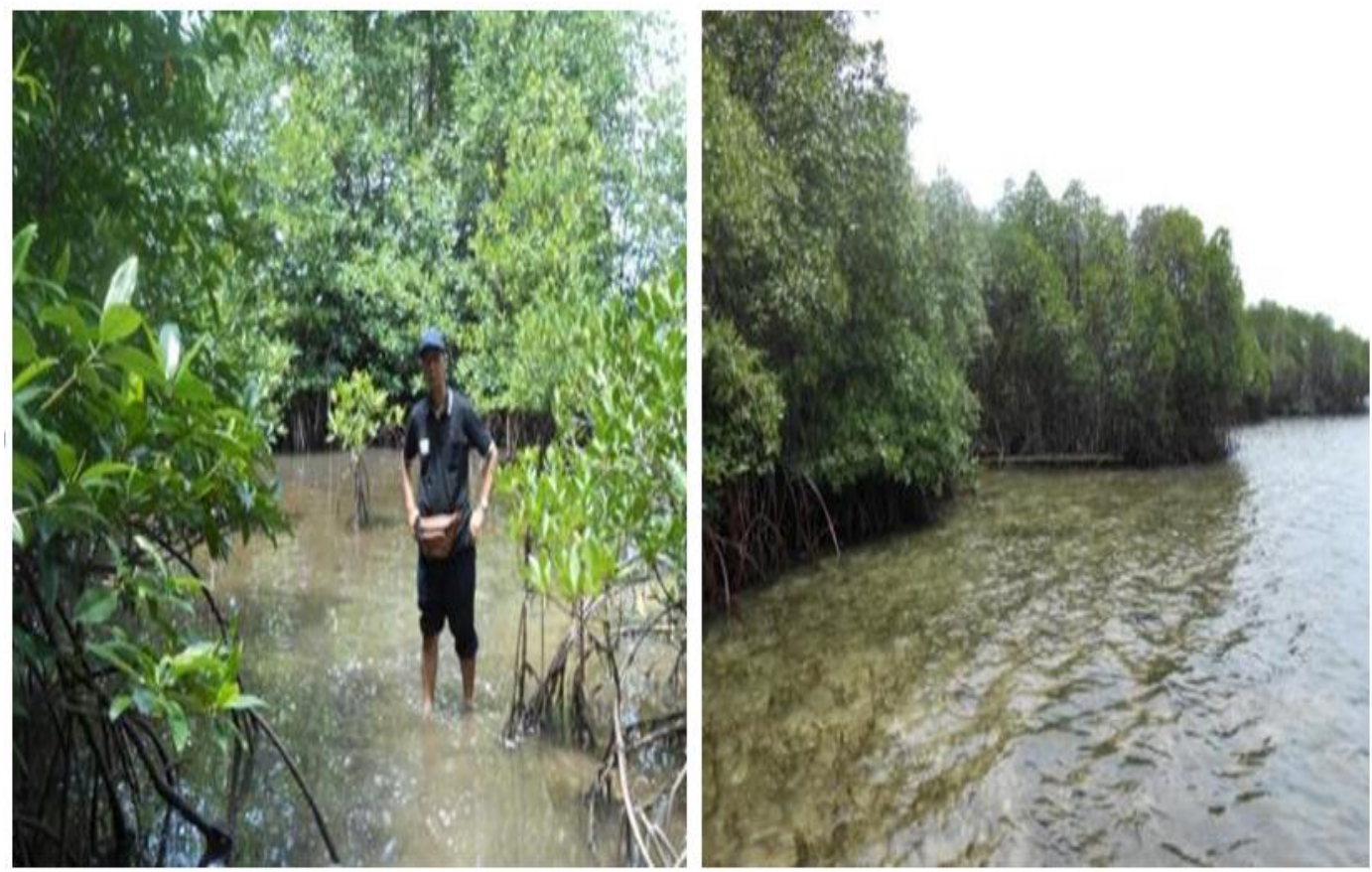

Gambar 2. Ekosistem hutan mangrove di Pulau Enggano

Ekosistem terumbu karang di Kawasan Pulau Enggano tersebar di perairan Tanjung Lakoaha, Tanjung Kioyeh, Tanjung Keramai, Tanjung Labuha, Tanjung Kahabi, Teluk Harapan dan Kaana, sekeliling Pulau Dua, Pulau Merbau dan Pulau Satu. Gambaran kondisi tutupan karang di beberapa lokasi ekosistem terumbu karang di Pulau Enggano disajikan pada Tabel 1 berikut ini. 
Tabel 1. Kondisi Tutupan Habitat Terumbu Karang di Kawasan Pulau Enggano (\%)

\begin{tabular}{|c|c|c|c|c|c|c|}
\hline No. & $\begin{array}{l}\text { Kategori } \\
\text { Habitat }\end{array}$ & $\begin{array}{l}\text { Pulau } \\
\text { Satu }\end{array}$ & $\begin{array}{l}\text { Teluk } \\
\text { Kiyaba }\end{array}$ & $\begin{array}{l}\text { Pulau } \\
\text { Dua* }\end{array}$ & $\begin{array}{l}\text { Pulau } \\
\text { Merbau** }\end{array}$ & $\begin{array}{l}\text { Rata- } \\
\text { Rata }\end{array}$ \\
\hline 1 & $\begin{array}{l}\text { Karang } \\
\text { hidup }\end{array}$ & 46,03 & 42,88 & 32,22 & 20,37 & 35,38 \\
\hline 2 & Biota lain & 0,00 & 8,20 & 0,54 & 2,97 & 2,93 \\
\hline 3 & Karang mati & 51,39 & 0,00 & 46,53 & 24,91 & 30,71 \\
\hline 4 & Algae & 0,00 & 0,00 & 0,11 & 0,00 & 0,03 \\
\hline 5 & Abiotik & 2,58 & 48,92 & 20,20 & 51,75 & 30,87 \\
\hline Total & & 100 & 100 & 100 & 100 & \\
\hline
\end{tabular}

Berdasarkan kriteria baku kerusakan terumbu karang (Keputusan Menteri Negara LH No. 4 Tahun 2001), kondisi terumbu karang di Kawasan Pulau Enggano kategorinya sedang. Namun di Pulau Merbau, kondisi tutupan karang hidup yang hanya $20,37 \%$, yang berarti kategorinya buruk. Menurut Bierd et.al. (2005) dalam Prasetia (2007), karang mati yang mendominasi substrat dasar perairan menunjukkan besarnya tekanan ekologis perairan seperti penangkapan ikan dengan bahan peledak dan sianida. Menurut DKTNL (2006), rusaknya terumbu karang diakibatkan oleh faktor alam dan faktor manusia, seperti gempa, aktivitas penangkapan ikan dengan menggunakan bahan peledak ataupun bahan kimia dan akibat terkena jangkar kapal. Hal ini dipertegas oleh Soleh (2004) salah satu faktor yang membuat tingginya komponen abiotik adalah penggunaan bahan peledak yang menyebabkan hancurnya karang menjadi Rubble.

Potensi lainnya yang berperan penting adalah padang lamun. Komunitas lamun di Kawasan Pulau Enggano ditemukan di Desa Kahyapu, Kaana, Malakoni, Apoho, dan sepanjang pesisir pantai sampai ke wilayah perairan Pulau Satu (wilayah Sebalik). Hasil penelitian bersama Arianto et al (2013) dan Astini (2014) mendapatkan beberapa jenis lamun yang terdapat di perairan Pulau Enggano yaitu Cymodocea rotundata, Cymodocea serrulata dan Sryngodium isoetifolium.

Menurut Mckenzie (2008), salah satu peranan penting dari padang lamun adalah menyediakan tempat pemijahan, perlindungan untuk ikan dan udang yang mempunyai nilai perikanan, sedangkan Hemminga and Duarte (2000) dalam Nadiarti et al (2012) juga menjelaskan, bahwa fungsi hamparan padang lamun menyediakan habitat untuk berbagai bentuk kehidupan di perairan pantai dan sebagai tempat pengasuhan, perlindungan dan area mencari makan bagi banya jenis hewan, termasuk sejumlah ikan dan kerang-kerangan yang bernilai penting secara ekonomi. 


\section{Potensi Sumberdaya Ikan}

Jenis sumber daya ikan yang terdapat di wilayah perairan Pulau Enggano dapat dikelompokkan menjadi lima kelompok besar yaitu ikan pelagis besar (ikan cakalang, tongkol, tenggiri, madidihang, tuna albakor, layaran dll), ikan pelagis kecil (ikan kuwe, selar, belanak, kembung dll), udang (udang penaid, lobster), ikan demersal (ikan kakap merah, pari, kerapu, bawal, ekor kuning dll), dan ikan karang (Chaetodon reticulatus, C. barronesa, C. vagabundus, Zanclus cornutus dan Paracanthurus hepatus). Penangkapan ikan oleh nelayan menggunakan perahu tanpa motor dan perahu motor tempel. Alat penangkapan ikan yang digunakan antara lain jaring insang, trammel net, pukat payang, rawai, pancing tonda, jala, dan pancing ulur.

Potensi sumberdaya kelautan lainnya adalah mariculture (budidaya di laut) untuk rumput laut, lobster, dan teripang). Ada 5 (lima) spesies rumput laut di perairan sekitar Pulau Enggano, dua diantaranya adalah jenis Eucheuma dan Gelidium yang merupakan jenis rumput laut yang berekonomis penting. Lokasi yang cocok untuk mariculture adalah di perairan Teluk Tanjung Harapan (sepanjang tahun), perairan Teluk Labuho, perairan Teluk Kioyo, perairan Desa Kaana dan Kahyapu (tergantung kondisi musim).

Kawasan Pulau Enggano juga berpotensi dikembangkan sebagai obyek wisata bahari seperti selancar, memancing, wisata selam, snorkeling, wisata pantai pantai, berenang, dan wisata desa binaan. Lokasi wisata bahari terdapat di perairan Pulau Dua, Pulau Merbau, Kahyapu, Pantai Teluk Harapan, Teluk Labuho, Teluk Berhawe, Tanjung Kioyo, Tanjung Koomang, dan pantai di Kaana.

\section{Permasalahan}

Upaya pengelolaan sumberdaya wilayah pesisir pulau-pulau kecil menghadapi berbagai ancaman, seperti terjadinya penurunan kualitas lingkungan karena pencemaran, perusakan ekosistem dan penangkapan ikan yang berlebihan (overfishing), alih fungsi kawasan, kurangnya pemahaman masyarakat lokal terhadap keberadaan, fungsi dan peranan penting dari berbagai ekosistem pesisir dan laut di kawasan pulau-pulau kecil. Pengelolaan wilayah pesisir umumnya berhadapan dengan berbagai permasalahan yang bersifat kompleks.

Permasalahan yang kompleks pada wilayah pesisir, menyebabkan pengelolaannya harus didasarkan pada pemahaman mendalam dan evaluasi pemanfaatannya bagi manusia harus dipertimbangkan dengan arif terhadap faktor-faktor ekologi yang berperan dalam mendukung keberadaan ekosistem-ekosistem di wilayah pesisir. Pengelolaan sumberdaya pesisir dan laut di pulau-pulau kecil seperti halnya Pulau Enggano, secara terpadu menghendaki adanya keberlanjutan (sustainability) dalam pemanfaatan sumberdaya yang ada. Sebagai kawasan yang dimanfaatkan untuk berbagai sektor pembangunan, wilayah pesisir memiliki kompleksitas isu, permasalahan, peluang dan 
tantangan. Untuk merumuskan langkah strategis dalam mewujudkan visi dan misi pengelolaan Kawasan Konservasi Perairan Daerah (KKPD) Pulau Enggano maka perlu dipahamai isu-isu pokok dan permasalahan yang bersinggungan dengan pengelolaannya.

Selain dari faktor alamiah, wilayah pesisir juga menerima berbagai dampak yang disebabkan oleh aktivitas manusia (Flectcher and Smith, 2007). Tekanan dari aktivitas manusia terhadap ekosistem wilayah pesisir seperti terhadap ekosistem hutan mangrove dan ekosistem terumbu karang dikenal juga dengan istilah antropogenik. Wilayah pesisir dan laut merupakan tempat kegiatan mencari nafkah bagi sebagian besar masyarakat yang bermukim di kawasan pesisir. Aktifitas ekonomi masyarakat yang terjadi di sekitar KKPD akan memberikan tekanan pada kondisi sumberdaya wilayah pesisir dan laut yang terdapat di sekitar kawasan.

Pertambahan penduduk yang terjadi dan berakumulasi dari tahun ke tahun jelas akan memberikan tekanan terhadap wilayah pesisir/konservasi di kawasan Pulau Enggano baik langsung maupun tidak langsung. Tekanan dari penduduk yang tampak jelas adalah kebutuhan penduduk untuk memenuhi kebutuhan ekonomi, kebutuhan pembangunan (fasilitas umum dan fasilitas sosial), pemukiman, lahan pertanian dan juga kebutuhan sosial budaya masyarakat. Data julmlah penduduk Pulau Enggano pada Tahun 2004 adalah 2.406 jiwa, pada Tahun 2006 sebanyak 2.758 jiwa, dan pada Tahun 2013 adalah sebanyak 2.864 jiwa. Dapat dilihat bahwa dari waktu ke waktu terjadi peningkatan jumlah penduduk yang akan berdampak pada bertambahnya kepentingan-kepentingan untuk pemenuhan kebutuhan hidup penduduk tersebut.

Penduduk yang mendiami desa-desa di kawasan konservasi perairan Pulau Enggano umumnya bekerja sebagai petani dan nelayan. Walaupun jumlah penduduk masih sedikit, namun tekanan terhadap ekosistem pesisir, pantai dan laut yang ada di kawasan Pulau Enggano cukup tinggi. Dampak dari tekanan aktivitas penduduk terhadap ekosistem pesisir di Pulau Enggano sangat nyata pada ekosistem terumbu karang. Hasil penelitian Bakhtiar dan Ta'alidin (2013), menjelaskan bahwa bahwa dari empat lokasi pengamatan terhadap kondisi terumbu karang di Pulau Enggano, rata-rata tutupan karang hidup adalah 35,38\%, karang mati $30,71 \%$ dan abiotik $30,87 \%$. Hal ini perlu mendapat perhatian, bahwa perlu upaya pengelolaan agar kondisi terumbu karang tersebut tidak menjadi semakin rusak.

Tekanan penduduk terhadap potensi sumberdaya pesisr dan laut di Pulau Enggano juga dapat dilihat dari menurunnya populasi teripang (Holthuroidea) di perairan Pulau Enggano. Nelayan sekarang sudah semakin sulit untuk mencari teripang, terutama dalam 4 tahun terakhir ini. Sekarang ini nelayan di Pulau Enggano sudah mencari teripang sampai pada kedalaman perairan 30-50 m, karena tidak bisa lagi menemukan teripang di sekitar perairan pantai dan padang seperti waktu-waktu sebelumnya (Ta'alidin, 2014). Masyarakat di Pulau Enggano juga harus diberi pemahaman dan tanggungjawab yang besar untuk melestarikan 
potensi sumberdaya wilayah pesisir yang menjadi sumber penghidupan mereka melalui program konservasi kawasan perairan daerah yang ditetapkan secara bersama dan bersifat legal-formal.

\section{Penangkapan Ikan Secara Ilegal (Illegal Fishing)}

Terjadinya degradasi kualitas dan potensi sumberdaya wilayah pesisir dan laut, terutama sumberdaya hayati ekosistem terumbu karang dan ikan salah satunya disebabkan oleh maraknya praktek penangkapan ikan illegal (illegal fishing) di berbagai perairan laut di Indonesia. Masalah illegal fishing merupakan ancaman yang sangat serius bagi kelestarian dan keberlanjutan sumberdaya wilayah pesisir, sehingga harus ditanggulangi juga dengan serius.

Ekosistem terumbu karang yang mengalami kerusakan, juga disebabkan adanya praktek penangkapan ikan illegal (illegal fishing). Berdasarkan hasil wawancara dengan kelompok masyarakat nelayan Pulau Enggano, kegiatan illegal fishing ini berupa penangkapan ikan menggunkan bom dan racun sianida. Pulau Enggano yang terletak di perairan Samudera Hindia, jauh dari daratan Pulau Sumatera, memang rentan terhadap praktek illegal fishing baik oleh kapal-kapal penangkapan ikan dari wilayah lain di Indonesia maupun oleh kapal-kapal asing.

Penegakan dan penguatan hukum secara terpadu, membangun kesatuan pandangan dari berbagai pihak yang berkepentingan dengan pelestarian sumberdaya wilayah pesisir dan pembangunan berkelanjutan, dan mengaktifkan peranan masyarakat dalam melakukan pengawasan sumberdaya perikanan dan kelautan melalui Siswasmas (Sistem Pengawasan Masyarakat) terutama masyarakat nelayan, merupakan beberapa alternative untuk menanggulangi praktek illegal fishing.

\section{Penangkapan Penyu}

Perairan Pulau Enggano diketahui mempunyai sumberdaya penyu laut yang cukup potensial. Penyu laut dapat dijumpai dan dilihat di tepi tubir yang terdapat di pesisir pantai Pulau Enggano. Beberapa lokasi yang biasa menjadi tempat akitifitas penyu bertelur adalah disekitar Teluk Labuho (Teluk Kopi) Teluk Abeha, Teluk Kioyo, Teluk Ahai (Sawang Pasir) dan dua lokasi di teluk Malakoni. Konflik kepentingan kelompok dan masyarakat dengan pelestarian sumberdaya pesisir dan laut di Pulau Enggano salah satunya adalah penangkapan penyu untuk keperluan acara adat-budaya di kalangan masyarakat. Penangkapan penyu tanpa menghiraukan pelestariannya akan menyebabkan penurunan jumlah populasi penyu dialam yang sudah langka dan terancam punah.

Sangat diperlukan adanya pemahaman yang mendalam dan kesadaran yang tinggi di kalangan masyarakat terhadap pentingnya kaidah-kaidah pelestarian sehubungan dengan pemanfaatan potensi sumberdaya penyu laut secara rasional dan berimbang. Masyarakat di Pulau Enggano harus mengetahui kadiah-kaidah pemanfaatan dan 
pengelolaan penyu laut haruslah merujuk pada nilai-nilai konservasi dan azas ramah lingkungan.

\section{Pemanfaatan dan Pengelolaan Potensi Wisata Belum Optimal}

Sekitar lokasi KKPD Pulau Enggano terdapat obyek wisata yang dapat dijadikan potensi wisata baik wistawan domestik maupun wisatawan mancanegara seperti ekowisata, wisata selam, pemancingan, perkemahan, jelajah hutan mangrove, snorkeling, dan penampakan ikan paus.

Potensi wisata alam yang ada terutama ekowisata belum termanfaatkan dengan baik sehingga belum dapat menjadi salah satu sumber penghasilan bagi pemerintah maupun bagi masyarakat di sekitarnya. Pengembangan pariwisata sekitar kawasan KKPD Pulau Enggano, tetap harus memerlukan pengpenelitian dan analisa dampak untuk dapat diantisipasi.

\section{Kelembagaan}

Belum ada lembaga formal yang aktif mengelola potensi sumberdaya pesisir dan laut di Pulau Enggano. Perlindungan terhadap ekosistem-ekosistem wilayah pesisir dan laut di kawasan Pulau Enggano selama ini dilakukan melalui kesepakatan adat dan budaya masyarakat yang merupakan suatu kearifan lokal. Selain itu di beberapa desa di Pulau Enggano, sudah ada peraturan desa (Perdes) yang diberlakukan untuk mengatur pemanfaatan dan pengelolaan ekosistem wilayah pesisir, seperti pelarangan penebangan hutan mangrove. Belum adanya lembaga yang mengelola sumberdaya wilayah pesisir dan laut di Pulau Enggano disebabkan oleh terbatasnya SDM, minimnya upaya untuk meningkatkan kapasitas dan kemampuan personil lembaga formal maupun non-formal, dan terbatasnya fasilitas pendukung yang dapat dipergunakan oleh lembaga-lembaga tersebut untuk mengelola kawasan konservasi penyu secara profesional. Kedepannya, untuk penetapan KKPD Pulau Enggano, memerlukan adanya lembaga pengelola yang bersifat formal.

\section{Rencana Pengelolaan Jangka Panjang dan Jangka Menengah}

Garis besar kebijakan pengelolaan KKPD Pulau Enggano diarahkan untuk pemanfaatan kegiatan pariwisata dan perikanan berkelanjutan. Kebijakan pemanfaatan untuk pariwisata, khususnya adalah wisata bahari berbasis potensi lingkungan, yaitu ekowisata (ecotourism).

Rencana Jangka Panjang (RJP) ini merupakan arah kebijakan pengelolaan KKPD Pulau Enggano dan perairan laut sekitarnya. Masa berlaku RJP ini adalah selam 20 (dua puluh) tahun, dan sesuai dengan ketentuan, akan ditinjau ulang paling lama untuk setiap 5 (lima) tahun sekali. 
Target pengelolaan KKPD Pulau Enggano paling tidak pada periode Rencana Pengelolaan Jangka Menengah (RPJM) IV, KKPD Pulau Enggano telah memiliki mekanisme pendanaan sendiri (sistem dana mandiri). Target lainnya adalah terciptanya berbagai kegiatan usaha yang mempunyai korelasi dengan pengelolaan KKPD yang berdampak positif untuk peningkatan ekonomi masyarakat setempat, dan sekaligus terjaganya KKPD Pulau Enggano secara berkelanjutan. Visi Pengelolaan Kawasan Konservasi Perairan Daerah (KKPD) Pulau Enggano Kabupaten Bengkulu Utara adalah "Mewujudkan pengelolaan dan pemanfaatan Kawasan Konservasi Perairan Enggano secara optimal, terpadu, dan berkelanjutan, sehingga bermanfaat bagi kesejahteraan dan kemakmuran masyarakat".

Adapun misi Rencana Pengelolaan KKPD Pulau Enggano adalah sebagai berikut :

- Meningkatkan koordinasi antar instansi terkait, pemerintah dan seluruh stakeholder dalam perencanaan, pemanfaatan dan pengawasan sumberdaya wilayah pesisir dan laut.

- Menyelamatkan penyu, teripang, lobster dan ikan hias karang dari ancaman kepunahan.

- Merehabilitasi ekosistem terumbu karang yang mengalami degradasi.

- Melestarikan habitat tempat peneluran penyu di KKPD.

- Penyadaran Masyarakat di dalam dan di luar kawasan KKPD terkait status spesies penyu saat ini sebagai biota yang dilindungi dan langka keberadaannya.

- Meningkatkan kesejahteraan masyarakat sekitar kawasan melalui pola kemitraan.

- Membangun sarana-prasarana yang memadai, sistem pengelolaan adaptif dengan dukungan pendanaan secara berkelanjutan.

- Mempertahankan keutuhan, kualitas dan daya dukung kawasan untuk memberikan manfaat bagi perikanan berkelanjutan dan pariwisata bahari pada zona pemanfaatan pariwisata dan kawasan disekitarnya dan pengembangan pendidikan dan penelitian kelautan dan perikanan.

Berdasarkan Visi Pengelolaan KKPD Pulau Enggano, serta memperhatikan semua isu-permasalahan, untuk mewujudkan tercapainya Visi, Misi, Tujuan dan Sasaran Pengelolaan KKPD, ditetapkan 3 (tiga) strategi utama, yaitu Pembentukan dan Penguatan Kelembagaan, Penguatan Pengelolaan Potensi dan Sumberdaya KKPD, dan Penguatan Sosial, Ekonomi dan Budaya.

Rencana Pengelolaan Jangka Menengah (RPJM) KKPD Pulau Enggano merupakan penjabaran dari visi, misi, tujuan, sasaran dan strategi pengelolaan KKPD yang berlaku selama 5 (lima) tahun untuk setiap periode pengelolaan selama kurun waktu 20 tahun. Rencana Pengelolaan Jangka Menengah ini meliputi berbagai program untuk mewujudkan strategi pengelolaan KKPD yang telah ditetapkan. Untuk 20 tahun masa pengelolaan KKPD, maka dibagi dalam 4 tahapan RPJM, yaitu RPJM I, RPJM II, RPJM III dan RPJM IV. Setiap RPJM tersebut 
memuat target-target tertentu yang harus dicapai pada akhir RPJM. Rencana kerja tahunan pengelolaan KKPD disusun berdasarkan rencana jangka menengah dalam bentuk rencana kegiatan dan anggaran yang disusun setiap satu tahun dengan memuat uraian kegiatan, penanggungjawab, waktu pelaksanaan, alokasi anggaran dan sumber pendanaan. Rencana Kerja Tahunan (RKT) disusun berdasarkan RPJM I. Rencana Kerja Tahunan untuk periode RPJM II disusun berdasarkan hasil evaluasi pelaksanaan RKT pada RPJM I. Dan demikian untuk seterusnya pada setiap periode RPJM III dan RPJM IV.

Zonasi dalam kawasan konservasi adalah pembagian kawasan menjadi beberapa zona melalui penetapan batas-batas fungsional sesuai dengan potensi sumber daya dan daya dukung, serta proses-proses ekologis yang berlangsung di dalamnya sebagai satu kesatuan ekosistem.

Berdasarkan PerMen KP Nomor PER.30/ MEN/2010 tentang Rencana Pengelolaan dan Zonasi Kawasan Konservasi Perairan, disebutkan bahwa zonasi di dalam kawasan konservasi perairan terdiri dari zona inti, zona perikanan berkelanjutan, zona pemanfaatan, dan zona lainnya. Hasil konsultasi publik dan pertemuan dengan tokoh masyarakat, ketua suku, kepala desa dan Camat Enggano, direncanakan ada 3 (tiga) zonasi kawasan, yaitu zona inti, zona pemanfaatan, dan zona perikanan berkelanjutan (Gambar 3, Gambar 4, dan Gambar 5). Lokasi KKPD ditetap di ujung Utara Pulau Enggano dengan akses terdekat adalah Desa Banjarsari dan diujung Selatan Pulau Enggano dengan akses terdekat adalah Desa Kahyapu (Gambar 3).
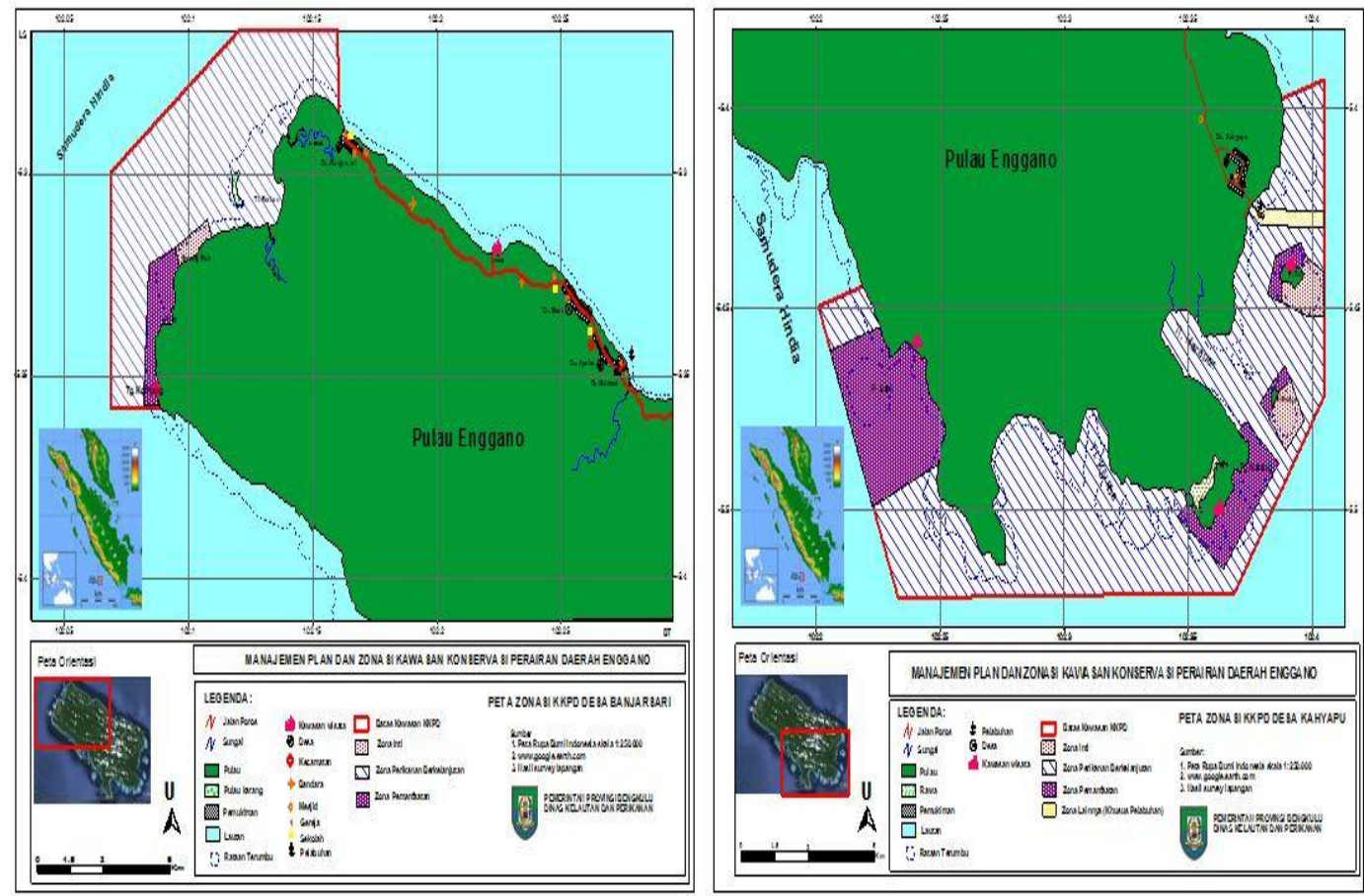

Gambar 3. Peta Zonasi KKPD Pulau Enggano di Desa Banjarsari dan Desa Kahyapu 

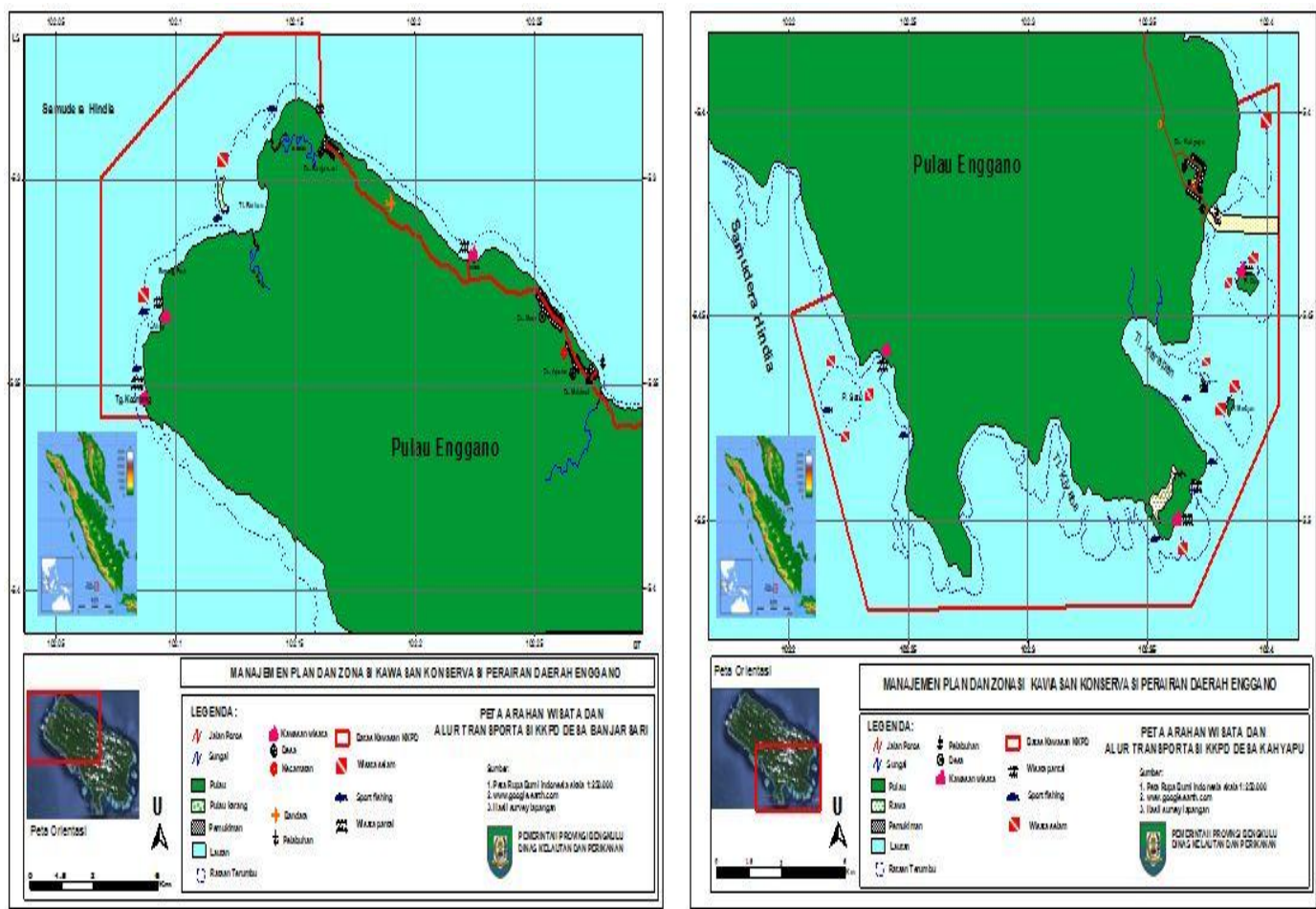

Gambar 4. Peta Arahan Wisata dan Alur Transportasi KKPD di Desa Banjarsari dan Desa Kahyapu
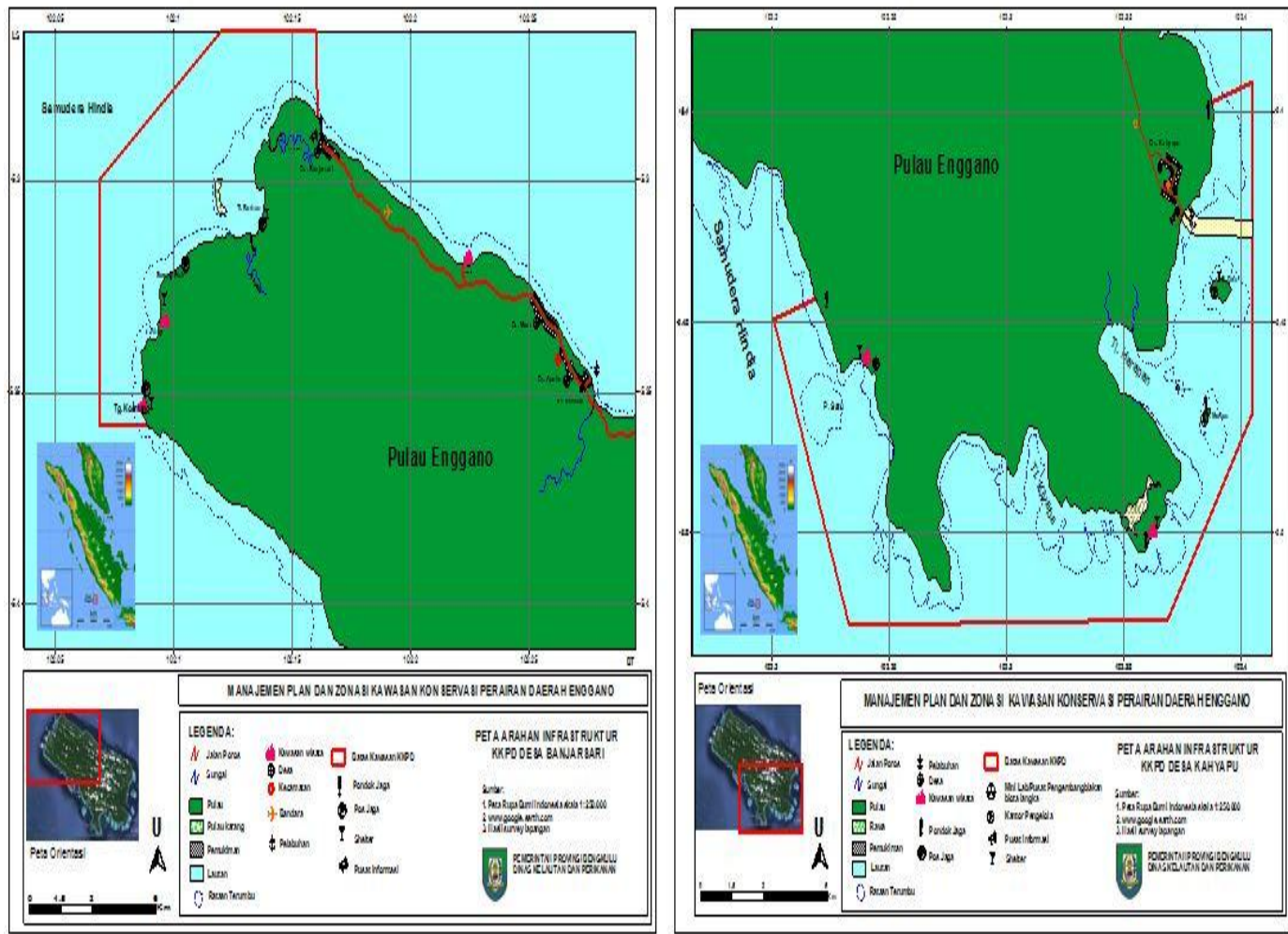

Gambar 5. Peta Arahan Infrastruktur KKPD di Banjarsari dan Desa Kahyapu 

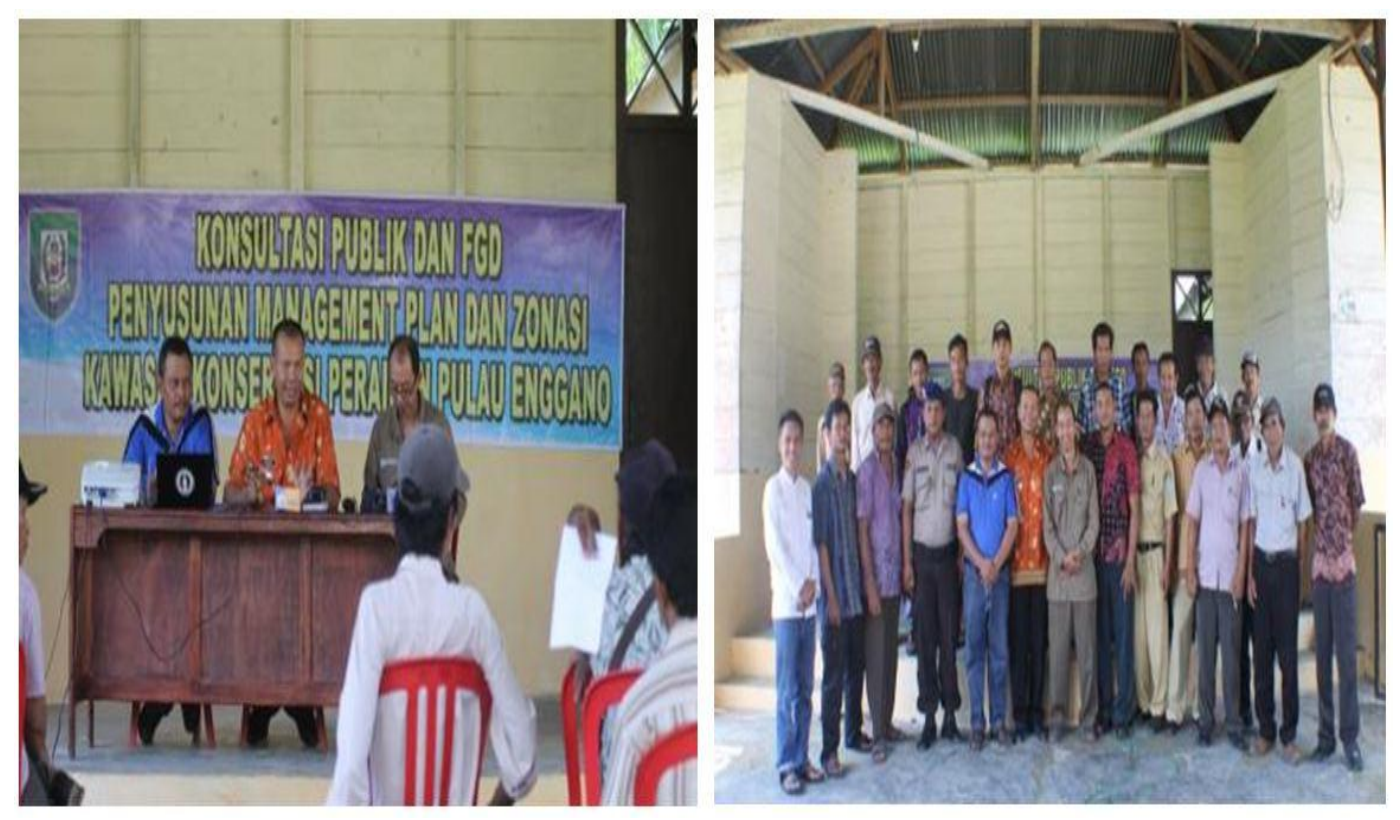

Gambar 6. Kegiatan Konsultasi Publik Penyusunan KKPD Pulau Enggano (Dokumen Penelitian)

\section{KESIMPULAN}

Kebijakan pengelolaan KKPD Pulau Enggano diarahkan untuk pemanfaatan kegiatan pariwisata dan perikanan berkelanjutan. Kebijakan pemanfaatan untuk pariwisata, khususnya adalah wisata bahari berbasis potensi lingkungan, yaitu ekowisata (ecotourism). Lokasi KKPD Pulau Enggano di tetapkan di Kawasan Desa Banjarsari dan Desa Kahyapu. Visi Pengelolaan Kawasan Konservasi Perairan Daerah (KKPD) Pulau Enggano Kabupaten Bengkulu Utara adalah "Mewujudkan pengelolaan dan pemanfaatan Kawasan Konservasi Perairan Enggano secara optimal, terpadu, dan berkelanjutan, sehingga bermanfaat bagi kesejahteraan dan kemakmuran masyarakat'. Pengelolaan KKPD Pulau Enggano untuk Rencana Jangka Panjang (RJP) adalah selama 20 tahun yang meliputi 4 tahapan Rencana Pengelolaan jangka Menegah (RPJM).

\section{UCAPAN TERIMA KASIH}

Penulis mengucapkan terimakasih kepada Dinas Kelautan dan Perikanan (DKP) Provinsi Bengkulu yang telah mendanai kegiatan penelitian ini; Ketua Adat Masyarakat Pulau Enggano dan seluruh Kepala Desa di Pulau Enggano yang telah memberikan data, informasi dan pandangan untuk kepentingan penyusunan Dokumen KKPD Pulau Enggano. Terimakasih juga disampaikan kepada Dr. Yar Johan, S.Pi. M.Si., Dr. (Cand.) Eko Nofridiansyah, S.Pi. M.Sc. dan Apriliansyah, S.Kel. yang sudah mendukung kegiatan secara aktif penyusunan Dokumen KKP Pulau Enggano. 


\section{DAFTAR PUSTAKA}

Agustini, N.T., 2014. Struktur Komunitas Ekosistem Mangrove di Desa Kahyapu Pulau Enggano. Skripsi Tidak Dipublikasikan). Program Studi Ilmu Kelautan Fakultas Pertanian Universitas Bengkulu.

Arianto, W., Zamdial Ta'alidin, R. Saepudin dan Dede Hartono, 2013. Valuasi Ekonomi Sumberdaya Hayati Pesisir dan Laut Kawasan Pulau Enggano. Lembaga Penelitian Universitas Bengkulu.

Arnef, Faddzul H.P. 2014. Luasan Tutupan Terumbu Karang dan Struktur Komunitas Karang di Pulau Merbau Enggano. Skipsi Prodi IImu Kelautan UNIB. Tidak di publikasikan.

Astini, L., 2014. Struktur Komunitas Lamun (Sea Grass) di Perairan Desa Kahyapu Pulau Enggano Kabupaten Bengkulu Utara Provinsi Bengkulu. Skripsi Tidak Dipublikasikan). Program Studi IImu Kelautan Fakultas Pertanian Universitas Bengkulu.

Astuti J., M. Nurdin dan A. Munir, 2008. Valuasi Ekonomi Sumberdaya Alam dan Lingkungan Pesisir Kota Bontang Kalimantan Timur. Jurnal IImiah Analisis, Edisi maret 2008, Vol. 5 No. 1, hal. 53-64.

Bakhtiar, D. dan Zamdial Ta'alidin, 2013. Keanekaragaman Jenis dan Distribusi Zooplankton di Perairan Pulau Enggano. Jurnal Mitra Bahari Vol. 7 No. 2, Mei-Agustus 2013 : 56-65.

Bappeda Bengkulu Utara dan Laboratorium Perikanan Unib, 2004. Rencana Strategis Khusus Pulau Enggano Kabupaten Bengkulu Utara. 77 hal.

Darsono, P., 1999. Pemanfaatan Sumberdaya Laut dan Implikasinya Bagi Masyarakat Nelayan. Jurnal IImiah Oseana P2O LIPI Jakarta, Volume XXIV Nomor 4 Tahun 2002, hal. 11-20.

DKTNL-Direktorat Konservasi dan Taman Nasional Laut. 2006. Pedoman Pelaksanaan Transplantasi Karang. DKP. Hal: 36.

Fletcher S, Smith HD (2007). Geography and coastal management, CoastalManagement 35(4):419-427.

Haloho, P., 2014. Struktur dan Zonasi Ekosistem Hutan Mangrove di Desa Kaana Kecamatan Enggano Kabupaten Bengkulu Utara. Skripsi Tidak Dipublikasikan). Program Studi IImu Kelautan Fakultas Pertanian Universitas Bengkulu. 
Keputusan Menteri Negara Lingkungan Hidup, No. 4. 2001. Tentang Kriteria Baku Kerusakan Terumbu Karang.

Khomarudin, R., Yennie Marini, Muchlisin Arief, Sartono Marpaung, Rossi Hamzah, dan Anneke K.S. Manoppo, 2016. Informasi Citra Satelit 92 Pulau-Pulau Kecil Terluar Indonesia. Edisi I. Pusat Pemanfaatan Penginderaan Jauh Deputi Bidang Penginderaan Jauh Lembaga Penerbangan Dan Antariksa Nasional (Lapan). 187 hal.

Mckenzie, L., 2008. Seagrass Educators Handbook. Seagrass-Watch $\mathrm{HQ}$ Northern Fisheries Centre, Cairn QLD 4870 Australia. 20 p.

Muqsit, A., 2013. Struktur Komunitas Terumbu Karang di Pulau Dua Enggano. Skripsi (Tidak Dipublikasikan). Program Studi Ilmu Kelautan Fakultas Pertanian Universitas Bengkulu.

Nadiarti, Etty Riani, Ita Djuwita, S. Buiharsono, A. Purbayanto dan H. Asmus, 2012. Challenging for Seagrass Management in Indonesia. Journal of Coastal Develpopment, Volume 15, Number 3, June 2012 : 234-242.

Prasetia, R. 2007. Kondisi Terumbu Karang Sebelum dan Sesudah Tsunami di Sabang, Nangroe Aceh Darussalam. IPB. Bogor.

Sobari, M.P., L. Adrianto dan N. Azis, 2006. Analisis Ekonomi Alternatif Pengelolaan Ekosistem Mangrove Kecamatan Barru Kabupaten Barru. Buletin Ekonomi Perikanan Vol. VI. No. 3 Tahun 2006, hal. 59-80.

Soleh, A. R. 2004. Perubahan Temporal Persentase Penutupan Substrat Dasar,Kondisi Ikan Karang, dan Preferensi Ikan Karang di Pulau Pramuka, Kepulauan Seribu, Tahun 2001-2003. IPB. Bogor.

Ta'alidin, Zamdial, 2014. Kondisi dan Pengelolaan Ekosistem Pesisir dan Laut Kawasan Pulau Enggano, Bengkulu Utara, Provinsi Bengkulu. Makalah disampaikan padaacara Konferensi Nasional (KONAS) IX P3K KKP RI, 18-21 November 2014 di Surabaya. 15 hal. 